\title{
LÍNGUA, FRONTEIRA E O ENSINO DE PORTUGUÊS COMO LÍNGUA ESTRANGEIRA
}

\author{
LENGUA, FRONTERA Y LA ENSEÑANZA DE PORTUGUÉS COMO LENGUA ESTRANJERA \\ LANGUAGE, BORDER AND PORTUGUESE TEACHING AS A FOREIGN LANGUAGE
}

\author{
Maria Tereza Nunes Marchesan" \\ André Gonçalves Ramos** \\ Universidade Federal de Santa Maria - UFSM, Santa Maria, BR
}

\begin{abstract}
RESUMO: Este trabalho apresenta uma discussão sobre a questão sociolinguística da fronteira Brasil-Uruguai como base para reflexões sobre a necessidade de uma abordagem específica de ensino de PLE para alunos uruguaios adultos oriundos dessa região. Considerando que as abordagens de ensino de português nas comunidades bilíngues diferem da abordagem do ensino de PLE e que as abordagens de ensino de PLE para não falantes de português tampouco coincidem com as peculiaridades de um ensino de PLE para falantes de DPU, argumentamos que as características sociolinguísticas da região fronteiriça Brasil-Uruguai devem ser consideradas no desenvolvimento de cursos específicos.

PALAVRAS-CHAVE: línguas em contato; português língua estrangeira; dialetos portugueses; Uruguai.
\end{abstract}

RESUMEN: Este trabajo presenta una discusión sobre la cuestión sociolingüística de la frontera Brasil-Uruguay como base para reflexiones sobre la necesidad de un abordaje específico de enseñanza de PLE para alumnos uruguayos adultos de esa región. Considerando que los abordajes de enseñanza de portugués en las comunidades bilingües difieren del abordaje de la enseñanza de PLE y que los abordajes de enseñanza de PLE para no hablantes de portugués tampoco coinciden con las peculiaridades de una enseñanza de PLE para hablantes de DPU, argumentamos que las características sociolingüísticas de la región fronteriza BrasilUruguay deben ser consideradas en el desarrollo de cursos específicos.

PALABRAS CLAVE: lenguas en contacto; portugués lengua extranjera; dialectos portugueses; Uruguay.

ABSTRACT: This paper presents a discussion about sociolinguistic aspects of the Brazilian-Uruguayan border aiming at reflecting on the needs for a specific PLE teaching approach to adult Uruguayan learners. If bilingual teaching contexts differ from monolingual ones and approaches to teach PLE for speakers of other languages than Spanish differ from those for DPU speakers, then sociolinguistics characteristics of border regions should be taken into account in developing a specific syllabus.

KEYWORDS: languages in contact, Portuguese foreign language, Portuguese dialects; Uruguay.

\section{INTRODUÇÃO}

Os estudos linguísticos que concebem a língua como mais que um simples meio de comunicação geralmente estão embasados em sólidos fundamentos teóricos que extrapolam a ideia de uma teoria da língua autossuficiente. O trabalho interdisciplinar que contrapõe, por exemplo, um conceito eminentemente linguístico como bilinguismo a um conceito proveniente de aspectos sociais, como diglossia, permite relacionar o caráter social, situacional e linguístico das seleções entre formas linguísticas diferentes. Sabe-se hoje em dia que o comportamento sociolinguístico dos falantes apresenta um alto grau de sistematicidade (BARRIOS; ORLANDO, 2002). De acordo com Barrios e Orlando (2002), dependendo das características sociais dos falantes e da situação comunicativa em que se encontram, é possível determinar probabilidades de aparição de determinados traços linguísticos. Essas características costumam ser bastante evidentes em regiões de contato entre línguas distintas mais que entre as relações entre variedades de uma mesma língua. A região fronteiriça do Brasil com o Uruguai, que é o nosso foco neste trabalho, apresenta esse quadro.

Assim, neste trabalho, buscamos apresentar uma discussão sobre a questão linguística da fronteira BrasilUruguai, enfocando relações histórico-culturais, com o fim de subsidiar reflexões sobre a necessidade de uma abordagem específica de ensino de português como língua estrangeira para alunos uruguaios adultos oriundos dessa região.

\footnotetext{
* Professora Doutora do Programa de Pós-Graduação em Letras da Universidade Federal de Santa Maria.

*** Mestrando do Programa de Pós-Graduação em Letras da Universidade Federal de Santa Maria.
} 
O tema proposto nos coloca na incumbência de abranger diversos domínios do conhecimento que contribuem para uma análise bem acurada das situações das línguas em contato. Para isso, percorremos um caminho que se inicia na caracterização da fronteira, isto é, a formação dos limites fronteiriços entre Brasil e Uruguai. Em seguida, traçamos um breve histórico dos estudos linguísticos já empreendidos na e sobre a região fronteiriça. Na sequência, discutimos conceitos-chave envolvidos nos estudos das relações entre as línguas (e as pessoas) nessas regiões. Apresentamos ainda um quadro da projeção da área de PLE, com as ações que vêm se desenvolvendo no Brasil e no exterior e destacamos a falta de trabalhos que enfocam o ensino de PLE em contextos específicos de fronteira. Concluímos com os encaminhamentos que esse percurso pode provocar na discussão sobre as abordagens de ensino de PLE.

\section{CARACTERIZAÇÃO DA FRONTEIRA RIVERA-LIVRAMENTO}

Para uma discussão sobre as características linguísticas da região da fronteira Brasil-Uruguai é necessário, primeiramente, tomá-la sob seu caráter histórico, uma vez que as situações linguísticas são resultados de processos histórico-culturais. Para isso, no caso de investigação sobre questões linguísticas em zonas de fronteira, torna-se importante conhecer o processo de formação das fronteiras políticas.

A partir do final do século XV, antes mesmo de os portugueses pisarem em solo americano, os reinos de Espanha e de Portugal começaram a disputar os territórios do "Novo Mundo". O Tratado de Tordesilhas, o primeiro dos acordos, foi assinado em 1494. Durante os séculos seguintes, tiveram lugar várias guerras pela conquista e demarcação de terras entre portugueses e espanhóis, principalmente ao sul do continente. Nos séculos XVI e XVII, os portugueses avançaram para o que hoje é o sul do Brasil, chegando a ocupar toda a região nordeste do Uruguai, que culminou com a fundação da Colônia do Santo Sacramento, nas margens do Rio da Prata em frente à cidade de Buenos Aires (TRINDADE; BEHARES; FONSECA, 1995).

No século XVIII, foram firmados muitos tratados diplomáticos, modificando várias vezes o traçado dos limites entre terras portuguesas e espanholas. A aparente calma foi quebrada, no século seguinte, com uma explosão de várias guerras nas regiões fronteiriças. No entanto, a partir dos anos 30 do século XIX, depois dos processos de independência, as linhas demarcatórias não mudaram em sua estrutura (TRINDADE; BEHARES; FONSECA, 1995). Segundo Trindade, Behares e Fonseca (1995, p. 14), apesar disso, grande parte do já território uruguaio ficou "nas mãos de brasileiros". Estes autores trazem dados do primeiro censo uruguaio de 1860 , que revela a presença de 40.000 brasileiros localizados, principalmente, no nordeste do país, o que representa $20 \%$ dos 200.000 habitantes uruguaios à época. Observada sob o ponto de vista da distribuição das terras nessa época, a presença brasileira em solo uruguaio é ainda mais significativa: recorrendo a dados apresentados por Mena Sergara, os autores Trindade, Behares e Fonseca (1995, p. 14-15) apontam que mais de $25 \%$ do território uruguaio era propriedade de brasileiros, dividido em 430 fazendas.

É nesse contexto que o governo uruguaio promove a construção de cidades uruguaias exatamente em frente a cidades brasileiras que já haviam se instalado sobre a linha divisória. Surgem, assim, as "cidades gêmeas", como é o caso de Cuareim (atual Artigas) em frente a Quarai, Villa Artigas (atual Rio Branco) em frente a Jaguarão e Villa Ceballos (atual Rivera) em frente a Sant'ana do Livramento (TRINDADE; BEHARES; FONSECA, 1995).

A partir da criação dessas cidades, o governo uruguaio passou a incentivar a colonização da fronteira, enviando colonos uruguaios, italianos e de outras origens para a região. Nesse momento, a escola passou a ter um importante papel para a criação de uma "identidade uruguaia”. A partir de 1880, foram criadas escolas nas quais o ensino de espanhol ganhou importância e primazia sobre o português. No entanto, a presença da língua portuguesa permaneceu como língua materna para a maioria dos moradores de origem lusitana, gerando um contexto de línguas em contato (TRINDADE; BEHARES; FONSECA, 1995).

Podemos perceber, assim, que a fronteira, ou melhor, a formação da fronteira política é um processo complexo que resulta em intrincadas relações sociais entre os habitantes. Concluímos, com isto, que as fronteiras não são meras linhas demarcatórias que separam dois países. De acordo com Sturza (2005, p. 47), "as fronteiras geográficas são preenchidas de conteúdo social", mesmo quando os agrupamentos são menores e menos populosos. 
Mota (2010), que empreende uma discussão desde um ponto de vista linguístico sobre o conceito de fronteira, propõe o termo "território fronteiriço" para melhor designar as relações linguísticas que aí se estabelecem. Segundo a autora,

Ao considerarmos que a fronteira pode constituir uma zona, uma região, composta por uma parcela dos territórios de dois Estados diferentes, onde se estabelecem trocas diversas entre as populações de ambos, podemos pensar que estamos diante de formas de apropriação que conduzem ao estabelecimento de um novo território: o território fronteiriço (MOTA, 2010, p. 21, grifo no original).

Nesse sentido, podemos substituir a noção de fronteira pela de zona de fronteira (território fronteiriço) e alargarmos, com isso, o campo de visão para as múltiplas interpenetrações que ocorrem nestes espaços. Estamos nos referindo ao que Mota (2010) designa como hibridação. Para esta autora, o aspecto linguístico da região fronteiriça Brasil-Uruguai é um dos mais evidentes casos de hibridação, pois aí é comum o uso de uma língua mista, comumente chamada de portunhol ${ }^{1}$.

Como vimos, o português foi a língua dos colonizadores de grandes porções de terras que acabaram ficando, na delimitação final, do lado uruguaio, o que não ocorreu na mesma proporção do lado brasileiro. Isto explica a presença do português no Uruguai e a menor (quase inexistente) presença do espanhol no Brasil. No entanto, com o passar dos anos, o contato entre português e espanhol nessa região e as diversas questões histórico-culturais que se seguiram provocaram o surgimento de características linguísticas muito peculiares desta região. Para Sturza (2005), nas zonas de fronteira, o contato humano e a mobilidade das populações contribuem para intensificar o cruzamento das línguas praticadas, criando, dessa forma, uma "dinâmica muito particular" no que diz respeito à extensão e o uso das línguas.

Atentando para esses fatos, é crescente o número de investigações sobre a questão linguística da região fronteiriça Brasil-Uruguai.

\section{ASPECTOS LINGUÍSTICOS DA FRONTEIRA}

Os aspectos linguísticos da região fronteiriça Brasil-Uruguai têm recebido bastante atenção de linguistas e sociolinguistas, principalmente uruguaios. Os pesquisadores brasileiros demoraram um pouco mais para encontrar aí um campo para pesquisa linguística. Apesar de um visível aumento de pesquisas brasileiras nessa área, no século XXI, a linguística brasileira talvez não tenha produzido ainda trabalhos suficientes para que se tenha um mapa completo da questão linguística fronteiriça, como alerta Sturza (2005). De fato, a forte presença da língua portuguesa em território uruguaio despertou o interesse, primeiramente, dos linguistas uruguaios, que passaram a estudar a situação das línguas na fronteira Brasil-Uruguai a partir da década de 1950.

A primeira obra que apresentou resultados de pesquisas nessa região foi "Dialecto fronterizo en el norte del Uruguay", de José Pedro Rona, publicado em 1965 (STURZA, 2005). Suas pesquisas sobre o português no território uruguaio desenvolveram-se sob uma perspectiva descritivista, abordando a questão a partir da noção de bilinguismo. A preocupação principal era distinguir variedades dialetais dessa língua (MOTA, 2010). Assim, ao pesquisar áreas rurais da fronteira, Rona concluiu que o contato histórico entre português e espanhol culminou no surgimento de três zonas dialetais: uma com uso de português, outra com uso de espanhol (com influência do português) e outra onde se usa um dialeto misto, com características do espanhol, mas com base portuguesa, o qual denominou "dialecto fronterizo" (MOTA, 2010; STURZA, 2005; 2006).

Na metade da década de 1960, as pesquisas de Hensey focaram a questão linguística nas comunidades fronteiriças urbanas (STURZA, 2005). Os resultados mostraram que o bilinguismo ocorre somente do lado uruguaio (MOTA, 2010). De acordo com Mota (2010), os brasileiros fronteiriços pesquisados por Hensey eram incapazes de produzir em outra língua, mesmo aqueles que conseguiam compreender o espanhol. Por outro lado, os muitos uruguaios bilíngues haviam aprendido o espanhol somente durante a fase escolar, como uma segunda língua (MOTA, 2010).

${ }^{1}$ Veja-se Lipski (2006) e Sturza (2006) para uma discussão sobre o termo portunhol. 
Como o ponto chave do trabalho de Hensey foi ter abordado a questão linguística na fronteira centrando na questão do bilinguismo, os aspectos histórico-linguísticos da constituição do sujeito não foram considerados (MOTA, 2010). No entanto, Hensey detectou uma característica funcional na escolha do código, isto é, a opção por uma ou outra língua estava em relação com a circunstância da interação (STURZA, 2006). Apesar disso, os resultados dos seus trabalhos não consideraram que "o bilinguismo fronteiriço não está equilibrado, dada a diferença no nível de domínio de uma das línguas e também por suas características enquanto línguas em situação de contato (...)" (STURZA, 2006, p. 60).

No inicio dos anos 80, Elizaincín, Behares e Barrios, pesquisadores uruguaios, uniram em seus estudos as perspectivas rural e urbana das pesquisas anteriores e concluíram que a situação linguística do norte do Uruguai se caracteriza pelo contato entre dialetos. Segundo Sturza (2005, p. 49), para estes autores, predominam, na zona rural e nas periferias urbanas, os falantes monolíngues de um dialeto do português (fronterizo). Já o bidialetismo ocorre na cidade, através do uso alternado de um dialeto do espanhol padrão e de um dialeto do português do Uruguai. Estes autores propõem, então, que não há apenas um português no Uruguai, mas sim distintos dialetos de base portuguesa, denominados Dialectos portugueses del Uruguay (DPU). A designação de DPU, proposta por Elizaincín, Behares e Barrios em 1981, indica, segundo Sturza (2006, p. 60), que "o português dominado pelos uruguaios fronteiriços já não é um português brasileiro, mas um português uruguaio afetado pelas transformações diacrônicas do português em território uruguaio".

No final dos anos 90, a pesquisadora Ana Maria Carvalho defende, em sua tese de doutorado, uma definição do português uruguaio que se assemelha a de Elizaincín, Behares e Barrios. No entanto, a autora exclui a noção de dialetos em convivência (STURZA, 2005). De acordo com Sturza (2005), a pesquisa de Carvalho revelou que o português usado na zona rural não seguiu a mesma rota que o português urbano, pois continua sendo usado por monolíngues. Assim, essa variedade corresponderia ao fronterizo de base portuguesa proposto por Rona na década de 50. Já o português falado pelos bilíngues nas cidades seria um “dialeto do português brasileiro urbano" (STURZA, 2005, p. 49).

Há em Mota (2010) uma discussão sobre as relações entre definições/denominações e as filiações teóricas e políticas. Estas determinam o uso e o surgimento das outras segundo os "modos de significar a relação política que se dá entre as línguas e os sujeitos que as praticam (e as estudam, acrescentamos) em diferentes condições sócio-históricas" (MOTA, 2010, p. 58).

Diante disso, podemos perceber que as peculiaridades e características das relações sociolinguísticas da região fronteiriça Brasil-Uruguai são muitas e complexas. Para a discussão que propomos estabelecer neste trabalho, no entanto, é de maior interesse o reconhecimento das diferenças das funções designadas a cada língua da fronteira.

Sturza (2006, p. 59) alerta que os falantes da fronteira utilizam "línguas com níveis de prestígio e funcionamento diferentes e as utilizam segundo os contextos em que estão inseridos: escolar, familiar, social”. Com efeito, os pesquisadores não ignoraram essa realidade. Segundo Sturza (2006), Rona e Hensey já haviam percebido que as variedades do português do Uruguai,

por serem menos prestigiosas e restritas ao uso familiar, entravam em conflito com a obrigatoriedade de aprender a língua nacional, o espanhol, tomada sempre como referência de língua padrão além da oficialidade que marcava a importância de seu aprendizado nas escolas da região. (STURZA, 2006, p.59).

Ao referirem à noção de conflito, estes autores nos abrem o campo para a discussão sobre a divisão funcional dos usos das línguas. Referimos-nos ao conceito de diglossia e outros que dele decorrem como deslocamento e normalização.

\section{INTERAÇÕES DESEQUILIBRADAS}

Falar em interações desequilibradas em contexto de relações entre línguas é falar de conflito linguístico. Conflito linguístico é um termo usado para contrapor à noção de contato entre línguas, partindo do pressuposto de que este não da conta do caráter de luta e contradição da qual a relação entre as línguas faz parte (HAMEL, 1988). Essa disputa, segundo Hamel (1988), muitas vezes, pode não surgir como uma guerra declarada, mas expressar-se como uma relação de forças transitoriamente equilibradas. Ainda assim, 
mudanças sociais abruptas podem desencadear um conflito aberto. Conflito linguístico, entretanto, não diz respeito a uma disputa entre línguas, mas sim ao aspecto linguístico de uma "luta" entre "grupos diferenciados por fatores socioeconômicos, étnicos e/ou socioculturais” (HAMEL, 1988, p.52)2.

Há um termo próprio para designar a relação desequilibrada entre línguas em conflito, é a diglossia. Apesar de ser concebida, primeiramente, para designar a situação em que diferentes variedades de uma língua, coexistentes, especializam-se em determinadas funções, servindo para propósitos específicos, este termo foi estendido, posteriormente, para comunidades em que as variedades em conflito têm status de línguas distintas (ROMAINE, 1996). De qualquer modo, segundo Romaine (1996), diglossia se refere ao fato de uma língua, com mais prestígio social, ser usada para funções "altas" (conferencias, leitura, escrita, meios de comunicação), enquanto a outra é reservada para funções "baixas" (conversas com amigos, familiares, etc.).

As sociedades diglóssicas, dessa forma, não se caracterizam somente pela alternância funcional de variedades ou línguas diferentes, mas também pelas restrições que essa situação impõe, principalmente, onde o bilinguismo não se constitui uma regra, mas, sim, uma exceção (ROMAINE, 1996). Meliá (1988), por exemplo, discutindo a situação diglóssica do Paraguai na década de 70, afirma que se trata de um caso de di-linguismo, uma vez que, apesar de o Paraguai ser bilíngue (espanhol e guarani), poucos paraguaios o eram. A importância dada pelos membros de uma sociedade ao fato de se usar a variedade adequada no contexto adequado é característico da compartimentalização que a diglossia provoca, porém, a questão conflituosa surge quando os habitantes consideram a variedade alta superior à outra ou às demais (ROMAINE, 1996). Assim, aquele que use uma variedade baixa em contexto errado será ridicularizado (ROMAINE, 1996, p. 66).

Concordamos, então, com Hamel (1988, p. 51) quando afirma que a diglossia é "parte integrante de um conflito intercultural, cujos aspectos sociolinguísticos se manifestam em uma relação assimétrica entre práticas discursivas dominantes (...) e práticas discursivas dominadas”. Para esse autor (1988), a diglossia se refere a uma relação de poder entre grupos sociais, na qual a sociedade dominante tenta impor seus padrões de apropriação e interpretação através de diversas formas de comunicação.

Entendida dessa forma, a noção de diglossia implica considerar as consequências linguísticas das disputas entre os grupos sociais dominantes, que utilizam as variedades prestigiadas, e os grupos sociais dominados, que utilizam as variedades estigmatizadas. A pressão causada pelo lado dominante chega, em alguns casos, a convencer muitos que estão do lado dominado, causando constrangimento e vergonha. Romaine (1996) cita o fato de pessoas chegarem ao ponto de negar que falam as variedades "baixas", No entanto, é possível que uma variedade ou língua "baixa" se mantenha, situação que está ligada ao caráter, muitas vezes, de pertencimento ou identidade. Porém, segundo Hamel (1988), esta questão não é tão simples, programas específicos de investigação precisam ser criados para estudar essas questões.

Apesar disso, esse autor propõe um esquema que permite ordenar os conceitos que estão em jogo nessas relações (figura 1, abaixo).

Essa figura revela que não há uma separação estrita entre língua "alta" e "baixa”. Há sim uma zona em que as línguas se entrecruzam, sobrepõem-se, e lutam por posição. As interações dadas neste espaço constituem, segundo o autor, formas específicas e indissociáveis das práticas sociais e culturais. É nesse espaço central que a disputa se materializa. Línguas (e pessoas) de diferentes espaços discursivos interagem num espaço onde se pode observar um "constante jogo de apropriação e refuncionalização, tanto na "superfície" como nos padrões de interação e interpretações subjacentes" (HAMEL, 1988, p. 55).

Entretanto, essa zona central não é estática. Pelo contrário, ela está sempre variando de acordo com a movimentação resultante das interações desequilibradas, da disputa por status. Para explicar melhor esse movimento precisamos considerar os conceitos de deslocamento e normalização $0^{3}$ propostos por Hamel (1988).

O processo histórico dos conflitos linguísticos, segundo Hamel (1998), tem a tendência a dissolver a diglossia, para um ou para outro polo, ainda que muitos processos nunca cheguem a exterminar uma das línguas por completo. Apesar disso, é preciso destacar que os conceitos de deslocamento e normalização são

\footnotetext{
${ }^{2}$ Todas as citações diretas feitas de Hamel (1998) são traduções nossas.

${ }^{3}$ Tradução nossa para desplazamiento e normalización, respectivamente.
} 
empregados do ponto de vista da língua "baixa". Assim, deslocamento refere-se ao processo de substituição da língua dominada pela dominante e normalização corresponde ao processo de contenção do avanço da língua "alta", e extensão da língua "baixa" para os âmbitos prestigiados.

Figura 1 - Relação de diglossia entre práticas discursivas (língua A) e práticas discursivas (língua B)

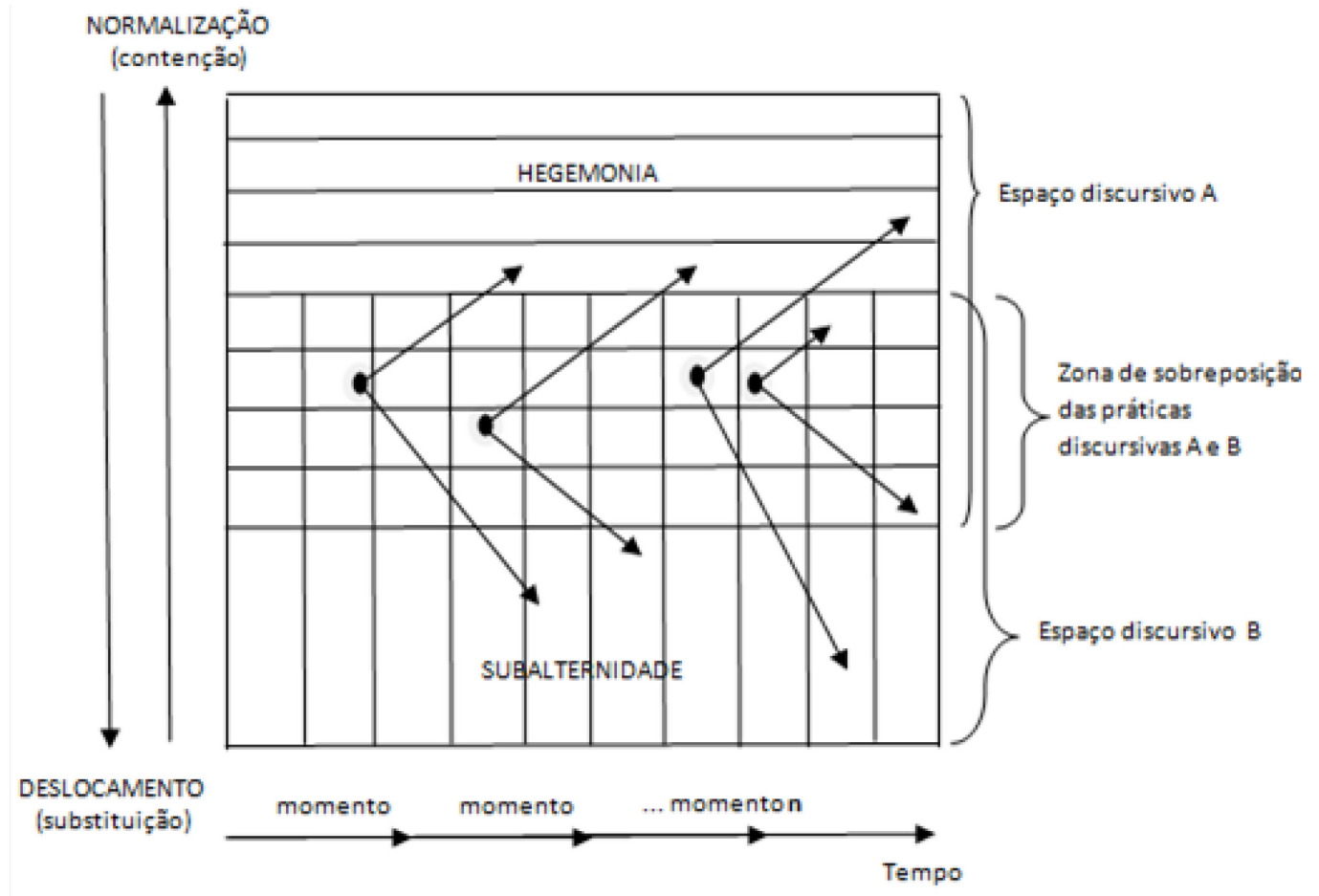

Fonte: Adaptado de Hamel (1988).

Como dissemos anteriormente, a diglossia faz parte dos processos socioculturais. Assim, para Hamel (1988, p. 64), o deslocamento e, principalmente, a consequente substituição "implica uma aculturação crescente dos grupos minoritários que se expressa como conflito entre experiência e práticas discursivas na língua B e em uma remodelação das bases interpretativas que sustentam essa experiência”. Já o conceito de normalização é definido como relegitimação e reinstitucionalização da língua dominada em determinados âmbitos sociais como, por exemplo, escolas, administração, reuniões de autoridades, etc. Hamel (1988) assevera ainda que o deslocamento é bastante comum, enquanto a normalização é mais rara, pois exige uma verdadeira "virada de mesa" na disputa por hegemonia que caracteriza a maioria das situações diglóssicas. A Catalunha, segundo este autor, apresenta um caso exemplar de normalização.

Ainda que proposto mais especificamente para discutir a questão diglóssica entre o espanhol e línguas indígenas autóctones em países andinos da América, o esquema proposto por Hamel nos da uma boa noção de como as questões socioculturais e linguísticas se relacionam de modo geral. Porém, é possível encontrar em Carvalho (1997) um estudo que aborda as noções de deslocamento e normalização referindo-se especificamente à fronteira Brasil-Uruguai, foco deste estudo. Os termos focusing e diffusing utilizados pela autora têm grande relação com o que discutimos acima sobre normalização e deslocamento. Colocados sob o ponto de vista da língua ou variedade "baixa", estes termos referirem-se, respectivamente, a uma situação de manutenção das formas típicas desvalorizadas e à movimentação no sentido da mudança para outras formas, menos estigmatizadas. A autora conclui que a transição de uma situação de "dialect focusing", que consistisse em uma forte incidência de variantes locais estigmatizadas, para uma situação de "dialect diffusing", implicaria numa limitação de espaço discursivo para aqueles que não acompanharem essa mudança.

Sobre o caso específico da fronteira Rivera-Livramento, Caravalho (1997) argumenta que o português falado em Rivera está sendo afetado pelas recentes mudanças sociais, tais como a urbanização e a alta exposição ao português standard brasileiro. Há, assim, uma mudança em curso que caminha de um dialeto com forte influência rural para uma versão mais urbana e menos estigmatizada.

Dessa forma, temos condições de compreender melhor a noção de diglossia no uso do português uruguaio e do espanhol em Rivera. Se retomarmos, agora, a explicação de Sturza (2006, p. 59) que diz que os falantes 
da fronteira utilizam "línguas com níveis de prestígio e funcionamento diferentes (português e espanhol) e as utilizam segundo os contextos em que estão inseridos: escolar, familiar, social”, podemos compreendê-la não como uma situação estática, mas como relações diglóssicas de conflito e luta que apresentam tendência para o deslocamento da variedade mais rural e em benefício de uma variedade com características mais urbanas e socialmente mais aceitas atualmente.

Carvalho (1997) vai além, propondo um continuum (quadro 1) que explica a movimentação em curso no português dos falantes riveirenses. Para a autora, os falantes de Rivera estariam em uma posição intermediaria entre os dois extremos. As variações encontradas mostrariam uma tendência para um ou pra outro lado, sempre de acordo com as características sociais e de estilo, as quais incentivam a normalização (focusing) ou o deslocamento (diffusing).

Quadro 1 - Continuum dialetal do português rural uruguaio (PRU) e português brasileiro urbano (PBU)

\begin{tabular}{|c|c|c|}
\hline \multirow{3}{*}{ Léxico: } & 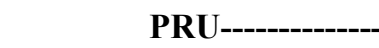 & ------PBU \\
\hline & Formas rurais & Formas não rurais \\
\hline & Empréstimos do espanhol & Sem empréstimos do espanhol \\
\hline \multirow{3}{*}{ Morfologia: } & Neologismos fronteiriços & Sem neologismos fronteiriços \\
\hline & Características rurais & Sem características rurais \\
\hline & Interferência do espanhol & Sem interferência do espanhol \\
\hline \multirow[t]{3}{*}{ Fonologia: } & Formas rurais & Sem formas rurais \\
\hline & Interferência do espanhol & Sem interferência do espanhol \\
\hline & normalização & $\Longrightarrow$ deslocamento \\
\hline
\end{tabular}

Fonte: Adaptado de Carvalho (1997).

É importante assinalar que todas as considerações sobre o uso da língua portuguesa não excluem, de modo algum, a posição muito forte (focusing) que o espanhol vem ganhando também a partir dessas mudanças sociais. Como vimos anteriormente, Elizaincín, Behares e Barrios já haviam sinalizado a presença urbana de um bidialetismo onde ocorre um uso alternado de um dialeto do espanhol padrão e de um dialeto do português do Uruguai. O que ocorre agora é uma tendência ao desaparecimento do PU e ascensão do PB no norte do Uruguai. Entretanto, uma discussão mais aprofundada sobre a questão do espanhol na fronteira fugiria dos propósitos deste trabalho.

Considerando a posição intermediaria que ocupam no continuum, podemos entender que muitos falantes uruguaios da fronteira Rivera-Livramento têm ainda o PU como sua língua materna. Esse fato é de grande importância para a compreensão da necessidade de uma abordagem específica de ensino de PB para alunos com essa característica. Por outro lado, nos faz entender que a distinção entre PB e PU é importante para uma atitude de (re)valorização do PU, apesar de não excluir a necessidade, de alguns, de aprender a variedade brasileira.

\section{O ENSINO DE PLE E O ENSINO PLE PARA FALANTES DE PU}

A área de ensino de português como língua estrangeira está crescendo significativamente. Apesar disso, há muito que se fazer para que essa área alcance padrões desejáveis de desenvolvimento. Almeida Filho (2007) apresenta uma avaliação do estado atual e do progresso dessa área, recorrendo a índices específicos de desenvolvimento e conclui que o Brasil apresenta um desempenho "claramente mediano" (ALMEIDA FILHO, 2007, p.47).

Os dados apresentados por Almeida Filho (2007) revelam que há iniciativas para a consolidação da área em todos os critérios arrolados pelo autor como necessários para a avaliação. Destacam-se nesse rol as bolsas concedidas pela Coordenação de Aperfeiçoamento de Pessoal de Nível Superior (CAPES) para alunos de países conveniados; o exame nacional de proficiência em língua portuguesa: o CELPE-BRAS; teses sobre PLE defendidas em programas de pós-graduação; a organização de eventos científicos específicos de divulgação; e existência de uma associação de professores, a SIPLE. O índice geral de 4.14 numa escala que 
vai até 10, no entanto, evidencia a necessidade de uma política linguística mais consistente, principalmente, no que respeita à criação de estratégias para o ensino de língua portuguesa e da cultura brasileira para falantes estrangeiros, tanto no país quanto no exterior.

Mais recentemente, Carvalho (2012) apresenta uma série de ações de planejamento linguístico que visam à promoção e difusão da língua portuguesa no cenário internacional, focando seus dados no âmbito da comunidade latino-americana. Destacamos, entre as ações, a Rede Brasileira de Ensino no Exterior, formada pelos Centros Culturais do Brasil (CCB), Institutos Culturais bilaterais (IC) e Leitorados brasileiros, que atua no continente americano, europeu, africano e asiático; os Programas de Estudantes Convênio, de graduação (PEC-G) e de pós-graduação (PEC-PG), que desde 1965 formam profissionais oriundos de países em desenvolvimento e que desde 1999 exige, como requisito à participação, a obtenção de nível intermediário no exame Celpe-Bras; a criação, em 2002, do Instituto Internacional da Língua Portuguesa, com sede em Cabo Verde, que tem como objetivo promover e difundir a língua portuguesa como veículo de cultura, educação, informação e acesso ao conhecimento científico, tecnológico e de utilização oficial em fóruns internacionais; o acordo binacional para a implementação de programas de ensino regular das línguas portuguesa e espanhola, firmado entre Brasil e Argentina, em 2005, que resultou na criação da Lei 16.161, que torna o espanhol língua de oferta obrigatória no Ensino Médio brasileiro a partir de 2010 e na Lei N. 26.468 que, por sua vez, tornou o português língua de oferta obrigatória na escola secundária argentina; o Projeto Escola Intercultural Bilíngue de Fronteira (PEIBF), que consiste na implantação de um sistema de escolas bilíngues português/espanhol ao longo de toda a fronteira com os países do MERCOSUL e que visa expor os estudantes à língua adicional desde as séries iniciais, além de despertar nas crianças a curiosidade pela cultura do país vizinho; a criação, em 2010, da Universidade Federal da Integração Latino-Americana (UNILA), que baseia-se em uma política educacional bilíngue português-espanhol voltada a questões do desenvolvimento latino-americano contando com professores e alunos de diferentes países latino-americanos.

Destacamos, de nossa parte, mais duas ações que contribuem para a ampliação da área de PLE: i) o Portal do Professor de Português Língua Estrangeira e ii) o Programa de Qualificação Docente e Ensino de Língua Portuguesa em Timor-Leste (PQLP/CAPES).

O Portal do Professor de Português Língua Estrangeira4 (PPPLE) é uma plataforma on-line, que tem como objetivo central oferecer à comunidade de professores e interessados em geral, recursos e materiais para o ensino e a aprendizagem do português como língua estrangeira. Procura atuar também na criação de estratégias de promoção, difusão e projeção do português no mundo, criando um sistema internacionalizado de gestão do ensino de PLE. Vinculado ao IILP, o Portal busca a cooperação entre os países membros da Comunidade de Países de Língua Oficial Portuguesa (CPLP), abrindo uma frente de trabalho e de negociação permanente que pode incrementar o número e a qualidade de ações comuns na área.

O PQLP, criado em 2005, através de Ajuste Complementar ao Acordo de Cooperação Educacional entre Brasil e Timor-Leste, é um programa atualmente gerido pela CAPES em parceria com o Ministério das Relações Exteriores, com a coordenação acadêmica da Universidade Federal de Santa Catarina (UFSC). O objetivo é a execução do ensino da língua portuguesa e outras atividades relacionadas à formação de docentes de diversos níveis das instituições de ensino timorenses. O programa, que já investiu mais de três milhões de reais e prevê uma ampliação para os próximos anos, envia anualmente cerca de cinquenta professores brasileiros para atuarem na elaboração e revisão de materiais didáticos, acompanhar professores timorenses na implementação de propostas, desenvolver e oferecer cursos de português como segunda língua, entre outras atividades (BRASIL, 2013). Apesar de ser língua oficial do país (Timor-Leste é membro efetivo da CPLP), o português em Timor-Leste está em processo de reconquista de um espaço que foi tomado pela língua indonésia durante o processo de ocupação do território timorense por mais de vinte anos (1975/1999), o que demanda esforços das autoridades locais e internacionais na área de política e planejamento linguísticos.

Retomando a proposta avaliativa apresentada por Almeida Filho (2007), podemos visualizar um quadro ilustrativo das pesquisas concluídas até aquele momento no âmbito especifico de PLE em programas de pós-graduação brasileiros. Destaca-se um maior número de pesquisas centradas na área de processos de aquisição. Ao analisar o quadro, é possível notar que - apesar de um grande interesse pela investigação do

\footnotetext{
${ }^{4}$ http://www.ppple.org/.
} 
processo de ensino-aprendizagem em contextos específicos, voltados, em sua maioria, para atender as necessidades de descrição, explicação e fundamentação do processo de ensinar e aprender - não são citados trabalhos que abordem o ensino de PLE em contextos de fronteira.

No que se refere ao ensino de PLE para falantes de PU, apesar de termos conhecimento de projetos que enfatizam o ensino de português e espanhol em áreas de fronteira (TRINDADE, BEHARES e FONSECA, 1995; BRASIL, 2008), esses trabalhos abordam o ensino nas comunidades bilíngues da fronteira, geralmente, destinado a crianças e em contexto de ensino básico regular. As práticas de ensinoaprendizagem, nessas condições, abordam geralmente o ensino de português sob o ponto de vista da língua materna. Assim, não temos à nossa disposição muitas referências ao ensino de português como língua estrangeira para falantes (adultos) de PU dessas regiões. Um trabalho que pode ser considerado exceção, nesse sentido, é a pesquisa de Diniz (2012). Apesar de não abordar especificamente o contexto de fronteira, a autora investigou as crenças de alunos do projeto de Capacitação em Português Língua Estrangeira Instrumental para Agentes do Governo Uruguaio, desenvolvidos em cumprimento a Acordos de Cooperação Técnica entre Brasil e Uruguai ${ }^{5}$, dos quais a UFSM é a instituição executora. O objetivo era verificar se as crenças de 75 alunos, policiais rodoviários uruguaios, sofreriam alterações a partir da abordagem de ensino instrumental. Além de teorizar sobre a mudança/ressignificação de crenças, o trabalho de Diniz (2012) elenca uma série de crenças de alunos uruguaios adultos com relação ao ensinoaprendizagem de PLE. Estudos como o de Diniz (2012) se fazem necessários para dar sustentação ao ensino de PLE para uruguaios adultos ${ }^{6}$.

\section{CONCLUSÃo}

No percurso que traçamos para esse trabalho, buscamos compreender o contexto sociolinguístico da região fronteiriça Brasil-Uruguai, a situação atual da área de PLE no âmbito nacional e internacional e o espaço reservado, nessa área, aos contextos específicos de ensino de PLE em regiões de fronteira.

No que diz respeito à área de PLE, considerando o grande impulso que a língua portuguesa recebeu nos últimos anos, cremos necessária uma avaliação atualizada do estado dessa área para uma julgarmos o atual impacto dessas ações político-linguísticas no desenvolvimento da área de PLE.

No que versa sobre o ensino de PLE no contexto sociolinguístico da fronteira Brasil-Uruguai, acreditamos que as características elencadas neste trabalho devem ser consideradas no desenvolvimento de cursos de português nesse contexto. Agindo dessa forma, nos colocamos de acordo com Carvalho (2010) quando afirma que,

ao buscar uma pedagogia sensível às diferenças culturais e linguísticas do alunato, o repertório linguístico da comunidade, assim como os diferentes valores sociais e símbolos identitários atribuídos a ele, deve ser considerado no desenvolvimento de objetivos, métodos e materiais didáticos. (CARVALHO, 2010 , p. 58).

Diante disso, ergue-se, a nosso ver, um desafio importante para a área de PLE. Trata-se de se considerar a formulação que diz que, se por um lado, a abordagem de ensino de português nas comunidades bilíngues difere da abordagem do ensino de PLE, por outro, as abordagens de PLE para não falantes de português tampouco coincidem com as peculiaridades de um ensino de PLE para falantes de PU. Seria o caso, então, de se buscar novos subsídios para sustentar essa abordagem totalmente original, para não dizer inusitada? Acreditamos que sim.

A questão que se destaca a partir de nossas considerações é a necessidade de se encontrar um caminho para o desenvolvimento do aspecto que acabamos de levantar, isto é, precisamos encontrar abordagens adequadas para um programa de ensino de PLE para falantes de PU que leve em consideração as características peculiares a que nos referimos neste trabalho.

\footnotetext{
${ }^{5}$ Informações disponíveis em http://www.abc.gov.br/Projetos/CooperacaoSulSul/Uruguai.

${ }^{6}$ Desenvolvemos, neste momento, pesquisa de mestrado intitulada "Falantes de PU aprendendo PB: análise de necessidades de agentes penitenciários uruguaios", com publicação prevista para março de 2015.
} 


\section{REFERÊNCIAS}

ALMEIDA FILHO, J. C. P. Índices nacionais de desenvolvimento do ensino de português língua estrangeira. In: ALMEIDA FILHO J. C. P.; CUNHA M. J. C. Projetos iniciais em português para falantes de outras línguas. Campinas, SP: PONTES EDITORES, 2007, p. 39-55.

BARRIOS, G.; ORLANDO, V. Marcadores sociales en el lenguaje: estudios sobre el español hablado en Montevideo. Montevidéu: GRÁFICOS DEL SUR, 2002.

BRASIL. Ministério da Educação. Escolas de Fronteira. Brasília e Buenos Aires, 2008. Disponível em $<$ http://portal.mec.gov.br/seb/arquivos/pdf/Escolafronteiras/doc_final.pdf > . Acesso em 14 de abril de 2014 .

Ministério da Educação. Brasil promove capacitação de professores no Timor-Leste. Brasília, 2013. Disponível em <http://portal.mec.gov.br/index.php?option=com_content\&view=article\&id=18486:brasilpromove-capacitacao-de-professores-no-timor-leste\&catid=225:sistemas $>$ Acesso em 10 de abril de 2014 .

CARVALHO, A. M. Variation and diffusion of Uruguayan Portuguese in a bilingual border town. In: ATAS I SIMPÓSIO INTERNACIONAL SOBRE O BILINGÜISMO: Comunidades e Indivíduos Bilíngües. Vigo, Espanha, 1997.

. Contribuições da sociolinguística ao ensino do português em comunidades bilíngues do norte do Uruguai. Pro-Posições [online], Campinas, v. 21, n. 3, p. 45-65, 2010.

CARVALHO, S. da C. Políticas de promoção internacional da Língua portuguesa: ações na América Latina. Trabalhos de Linguística Aplicada, Campinas, v. 51, n. 2, p. 459-484, jul./dez. 2012.

DINIZ, D. F. Crenças sobre ensino/aprendizagem no ensino instrumental de línguas. v.1, 162p. Dissertação (Mestrado em Letras), Universidade Federal de Santa Maria, 2012.

HAMEL, R. E. La política del lenguaje y el conflicto interétnico: problemas de investigación sociolingüística. In: ORLANDI, E. Política Lingüistica na América Latina. Campinas, SP: PONTES, 1998. p. 41-73.

LIPSKI, J. Too close for comfort? The genesis of portuñol/portunhol. In: FACE T.; KLEE C. Selected proceedings of the 8th Hispanic Linguistics Symposium. Somerville: CASCADILLA PROCEEDING

PROJECT, 2006.

MOTA, S. S. Linguas, sujeitos e sentidos: o jornal nas relações fronteiriças no final do século xix, início do século XX. 2010. 106 f. Dissertação (Mestrado em Letras: estudos linguísticos), Universidade Federal de Santa Maria, Santa Maria-RS, 2010.

MELIÁ, B. Diglosia en el Paraguay: o la comunicación desequilibrada. In: ORLANDI E. Política Lingüística na América Latina. Campinas, SP: PONTES, 1998. p. 111-119.

ROMAINE, S. El lenguaje en la sociedad: una introducción a la sociolingüística. Barcelona: ARIEL, 1996.

STURZA, E. R. Línguas de fronteira: o desconhecido território das práticas lingüísticas nas fronteiras brasileiras. Cienc. Cult. [online], São Paulo, v. 57, n. 2, p. 47-50, 2005.

Linguas de fronteira e política de línguas: uma história das idéias linguísticas. 2006. 168 f. Tese (Doutorado em Linguística), Universidade de Campinas, Campinas, 2006.

TRINDADE, A. M.; BEHARES, L. E.; FONSECA, M. C. Educação e linguagem em áreas de fronteira BrasilUruguai. Santa Maria, RS: PALLOTTI, 1995.

Recebido em 12/o9/2013. Aprovado em 06/04/2014. 